\title{
Aplicação do método do índice de qualidade (MIQ) para o estudo da vida útil de filés de tilápia do Nilo (Oreochromis niloticus) sem pele, armazenados em gelo
}

\author{
Quality index method (QIM) application on shef life estimation of \\ skinned fillets of Nile tilapia (Oreochromis niloticus) kept in ice
}

\author{
Karoline Mikaelle de Paiva Soares ${ }^{1 *}$; Alex Augusto Gonçalves ${ }^{2}$
}

\begin{abstract}
Resumo
O objetivo do presente trabalho foi desenvolver o Método do Índice de Qualidade (MIQ) para filé sem pele de tilápia do Nilo (Oreochromis niloticus), cultivada, e aplicá-lo no estabelecimento da sua vida útil. Os filés (média de $120 \mathrm{~g}$ cada) foram mantidos em caixas com gelo na proporção de 1:1 (filé:gelo) na temperatura média de $0^{\circ} \mathrm{C}$ e armazenados em câmaras de refrigeração $\left(4^{\circ} \mathrm{C}\right)$ por 18 dias. Para avaliar o frescor durante o armazenamento, realizaram-se análises sensoriais (MIQ) e físico-químicas (pH e Nitrogênio das Bases Voláteis Totais) a cada 72 horas, a partir do tempo zero, em triplicata. A vida útil máxima do filé sem pele de tilápia do Nilo, em gelo, foi estimada em 15 dias. O MIQ foi considerado eficiente na avaliação do frescor da tilápia do Nilo, já que a rejeição sensorial pelo MIQ foi determinante no estabelecimento da vida de prateleira.
\end{abstract}

Palavras-chave: Tilápia, frescor, análise sensorial, rejeição, vida de prateleira

\begin{abstract}
The objective of this study was to develop the Quality Index Method (QIM) for skinned fillets from farmed Nile tilapia (Oreochromis niloticus), and apply it in the establishment of its shelf life. The skinned fillets (120 g in average) were kept in boxes with ice in the proportion of 1:1 (fillet:ice) under average temperature of $0^{\circ} \mathrm{C}$ and stored at refrigeration chamber $\left(4^{\circ} \mathrm{C}\right)$ during 18 days. To evaluate the freshness during storage time sensory analysis (QIM) and physicochemical ( $\mathrm{pH}$ and TVB-N) were performed every 72 hours from time zero, in triplicate. The maximum life of the Nile tilapia fillet in ice was estimated at 15 days. The MIQ was considered effective in evaluating the freshness of the Nile tilapia, since the sensory rejection by MIQ was determinant in the shelf life establishment.
\end{abstract}

Key words: Tilapia, freshness, sensory analysis, rejection, shelf life

\footnotetext{
${ }^{1}$ Doutoranda em Ciência Animal, Programa de Pós Graduação em Ciência Animal, Dept ${ }^{\circ}$ de Ciências Animais, Universidade Federal Rural do Semi-Árido, UFERSA, Mossoró, RN. E-mail: karolinemikaelle@hotmail.com

${ }^{2}$ Prof. Dr., Programa de Pós Graduação em Ciência Animal, Dept ${ }^{\circ}$ de Ciências Animais, UFERSA, Mossoró, RN. E-mail: alaugo@ gmail.com

* Autor para correspondência
} 


\section{Introdução}

A tilápia do Nilo (Oreochromis niloticus) representa uma importante espécie introduzida na região Nordeste do Brasil em 1971. Atualmente, é uma das espécies mais cultivadas em sistemas de produção semi-intensivo e intensivo em todo o mundo. Dentre os principais fatores que tornam a tilápia uma das principais espécies cultivadas em todo o mundo, destacam-se: a sua grande capacidade de adaptação, a elevada resistência a doenças, rápido desenvolvimento, pequeno requerimento energético e alta aceitabilidade pelo mercado consumidor. Esta espécie ocupa, atualmente, o terceiro lugar no ranking mundial de peixes produzidos em cativeiro, e, sua produção continuará crescendo, pois o mercado consumidor de tilápia de cultivo vem crescendo nos países desenvolvidos, principalmente na Europa e na América do Norte, onde a procura por peixes de carne branca vem aumentando consideravelmente (GODOY, 2006; OMONDI; GICHURI; VEVERICA, 2001). Segundo dados do Ministério da Pesca e Aquicultura (2011), a criação de tilápia representa $39 \%$ do total da produção nacional de pescado, chegando a atingir $132 \mathrm{mil}$ toneladas/ano.

Acarne do pescado, de uma forma geral, apresenta elevada importância nutricional. O aproveitamento dos benefícios nutricionais da carne do pescado só é possível quando os fatores de qualidade deste alimento em termos de saúde pública e ausência de riscos ao consumidor forem garantidos, e por esta razão é fundamental o emprego de ferramentas de avaliação do frescor durante todo período de comercialização desses produtos. Os métodos de avaliação do frescor do pescado dividem-se em sensoriais, físico-químicos e microbiológicos, sendo a avaliação sensorial o método mais utilizado no setor de pescado e pelos serviços de inspeção sanitária em virtude do baixo custo, eficiência e praticidade (GERMANO; GERMANO, 2008; NUNES; BATISTA; CARDOSO, 2007).

Dentre os métodos de análise sensorial aplicados ao pescado, o Método do Índice de Qualidade (MIQ) destaca-se por ser específico para cada espécie, o que o torna mais fidedigno (OLAFSDÓTTIR et al., 1997). O MIQ é atualmente reconhecido como método de referência em pesquisas na área de qualidade sensorial de pescado e vem sendo adaptado para várias espécies como o salmão do atlântico - Salmo salar (SVEINSDOTTIR et al., 2003), merluza-Merluccius merluccius (BAIXASNOGUERAS et al., 2003), filé de bacalhau Gadus morhua (BONILLA; SVEINSDOTTIR; MARTINSDOTTIR, 2007), camarão branco Litopenaeus vannamei (OLIVEIRA; CLEMENTE; MÁRSICA, 2009), sépia - Sepia officinalis (SYKES et al., 2009), dentre outras.

O MIQ é um sistema utilizado para estimar o frescor e a qualidade do pescado, que tem se demonstrado rápido e eficiente (MARTINSDOTTIR et al., 2001; OLIVEIRA; CLEMENTE; MÁRSICA, 2009). De acordo com COSTELL (2002), o MIQ é baseado em avaliação objetiva dos principais atributos sensoriais de cada espécie de pescado usando um esquema composto por vários parâmetros sensoriais.

Este método é projetado de modo que um parâmetro de qualidade de um pescado muito fresco recebe pontuação zero e com o progresso da deterioração, que ocorre com o armazenamento em gelo, a pontuação vai aumentando até atingir a pontuação máxima que corresponde a três pontos para um determinado atributo de qualidade sensorial (BOGDANOVIC et al., 2012). A pontuação global resultante da pontuação de todas as alterações pós morte mensura o Índice de Qualidade (IQ). Como não é colocada ênfase excessiva em um único atributo de uma amostra, esta não pode ser rejeitada com base em um critério único e pequenas diferenças de resultados para qualquer um dos critérios não influenciam indevidamente a pontuação MIQ total (LUTEN; MARTINSDOTTIR, 1997; HYLDIG; NIELSEN, 1997).

Neste sentido, o presente trabalho teve por objetivo aplicar o MIQ para filés sem pele de tilápia do Nilo (Oreochromis niloticus) armazenados em gelo e estabelecer sua vida de prateleira através de métodos sensoriais e físico-químicos. 


\section{Material e Métodos}

Os exemplares de tilápia do Nilo (Orechromis niloticus), com peso médio de 650 gramas, foram obtidos diretamente do produtor, na Unidade Demonstrativa de Cultivo de Tilápias em Gaiolas, (Apodi, RN, Brasil) e abatidos por hipotermia, em água com gelo, na proporção 1:1 (água:gelo; temperatura aproximadamente $1^{\circ} \mathrm{C}$ ), atendendo aos preceitos de ética e bem-estar animal. Após o abate, os peixes foram acondicionados em gelo e transportados ao Laboratório de Tecnologia de Alimentos da Universidade Federal Rural do SemiÁrido (UFERSA), onde foram filetados, seguido da remoção da pele e embalado em sacos plásticos. Os filés, com peso médio de aproximadamente 120 gramas, foram acondicionados em caixas isotérmicas, com gelo em escama, e mantidos sob refrigeração (aproximadamente $0^{\circ} \mathrm{C}$ ).

A avaliação do estado de frescor foi realizada através de testes sensoriais e físico-químicos realizados durante todo o armazenamento, partindose de um tempo zero e repetindo-se em intervalo regulares de 72 horas.

\section{Análise sensorial (MIQ)}

A análise sensorial foi realizada através do MIQ, atendendo as normas de ética na pesquisa. Esta análise foi realizada no Laboratório de Tecnologia de Alimentos (UFERSA). A temperatura ambiental média foi estabilizada em $24 \pm 3^{\circ} \mathrm{C}$. O treinamento da equipe de julgadores foi realizado no mesmo espaço físico e nas mesmas condições ambientais.

A avaliação do estado de frescor e da qualidade sensorial das amostras foi realizada por uma equipe composta por três julgadores previamente treinados. O treinamento foi realizado durante sete dias, a cada 24 horas, utilizando-se duas amostras, por dia de avaliação. A finalidade do treinamento foi apresentar aos julgadores as características sensoriais típicas de um filé de tilápia fresco e deteriorado, e montar uma tabela com os atributos sensoriais necessários para a execução do MIQ.
O treinamento foi realizado utilizando esquema da metodologia MIQ desenvolvido por Bonilla, Sveinsdottir e Martinsdottir (2007). A cada análise do treinamento, foram listados, pela equipe, parâmetros sensoriais considerados significativos para avaliar a qualidade dos filés de tilápia resultando em um esquema preliminar. Este esquema preliminar foi utilizado e ajustado durante a execução do experimento definitivo resultando em um esquema MIQ definitivo para filé sem pele de tilápia do Nilo.

O tempo de armazenamento foi inicialmente projetado em 21 dias, porém o fim do período de estocagem ocorreu no $18^{\circ}$ dia, quando as amostras receberam a pontuação de IQ máxima do esquema.

Durante a análise sensorial, três amostras foram dispostas em bandejas previamente codificadas com números aleatórios. Os filés foram pontuados por cada um dos três julgadores, sendo que a média obtida dos escores de todos os julgadores para cada tempo de estocagem representou o IQ para o dia de estocagem estudado.

\section{Análises físico-químicas}

$\mathrm{O}$ pH foi medido através da aferição direta na musculatura do peixe utilizando um potenciômetro digital. O teor de Nitrogênio das Bases Voláteis Totais (N-BVT) foi medido através de adaptação de método de destilação proposto pelo Laboratório Nacional de Referência Animal (LANARA, 1981).

\section{Análise estatística}

Os dados obtidos foram submetidos à análise de regressão linear simples. A equação da regressão linear simples e o coeficiente de correlação $\left(r^{2}\right)$ entre o IQ e o tempo de armazenamento em gelo, foram calculados utilizando o software SigmaPlot for Windows V. 10 (Systat Software, Inc.). 


\section{Resultados e Discussão}

Desenvolvimento do método do índice de qualidade (MIQ)

O protocolo preliminar de avaliação do MIQ para filés de tilápia sem pele teve alteração no atributo "textura do filé". No esquema preliminar, a nota referente a este parâmetro variava de 0 a 2 pontos, ou seja: 0 - fresco, 1 - ligeiramente mole e 2 - mole. No esquema definitivo foi incluído o escore 3 referente a musculatura completamente autolisada, desfragmentando-se ao toque mais forçado dos dedos.
A presença de parasitas não foi considerada um aspecto significativo para avaliar a qualidade sensorial de filés de tilápia do Nilo estocados em gelo, o que ocorreu de forma contrária à forma considerada por Warm, Boknaes e Nielsen (1998) e Jensen e Jorgensen (1997) e de forma semelhante às consideradas por Odoli(2009)e Bonilla, Sveinsdottir e Martinsdottir (2007) que não relacionaram a presença de parasitas como parâmetro sensorial significativo para avaliar o frescor de filés de tilápia e bacalhau, respectivamente, através do MIQ. O protocolo final do MIQ para filés sem pele de tilápia do Nilo está representado na tabela 1 . A pontuação de IQ varia de 0 a 14 pontos.

Tabela 1. Esquema final do Método do Índice de Qualidade (MIQ), para avaliação sensorial de filés de tilápia do Nilo (Oreochromis niloticus) estocados em gelo.

\begin{tabular}{|c|c|c|c|}
\hline & ÂMETROS & CARACTERÍSTICAS & NOTA \\
\hline \multirow{20}{*}{ Musculatura } & \multirow{3}{*}{ Cor } & Brilhante, bege a rosa claro & $0($ ) \\
\hline & & Ligeiramente opaca, bege mais escurecido & 1() \\
\hline & & Beje opaca, intercalada com manchas rosadas escurecidas & 2() \\
\hline & \multirow{3}{*}{ Muco } & Transparente e fino & 0() \\
\hline & & Ligeiramente viscoso & $1($ ) \\
\hline & & Muito viscoso & 2() \\
\hline & \multirow{4}{*}{ Odor } & Fresco & 0() \\
\hline & & Não fresco, mas neutro & 1() \\
\hline & & Amoniacal & 2() \\
\hline & & Pútrido & 3() \\
\hline & \multirow{4}{*}{ Textura } & Firme & $0($ ) \\
\hline & & Ligeiramente mole & $1($ ) \\
\hline & & Mole & 2() \\
\hline & & Completamente autolisado, desfragmentando-se ao toque & 3() \\
\hline & \multirow{3}{*}{ Sangue } & Vermelho brilhante & 0() \\
\hline & & Rubro a vinho & 1() \\
\hline & & Amarronzado & 2() \\
\hline & \multirow{3}{*}{$\begin{array}{c}\text { Disposição das fibras } \\
\text { musculares }\end{array}$} & Sem abertura, poucas aberturas & 0() \\
\hline & & Com abertura em menos de $25 \%$ do filé & $1($ ) \\
\hline & & Com abertura em mais de $75 \%$ do filé & 2() \\
\hline \multicolumn{3}{|c|}{ ÍNDICE DE QUALIDADE } & $0-14$ \\
\hline
\end{tabular}

Fonte: Elaboração dos autores.

Aplicação do MIQ na estimativa da vida útil dos filés de tilápia do Nilo

A figura 1 representa o gráfico da curva de calibração do IQ para filés de tilápia do Nilo.
Observa-se uma equação linear do IQ em função dos dias de armazenagem em gelo. O IQ variou de 0 a 14 pontos. 
Figura 1. Curva de calibração do Índice de Qualidade (IQ) de filés sem pele de tilápia do Nilo (Oreochromis niloticus) estocada em gelo por 18 dias.

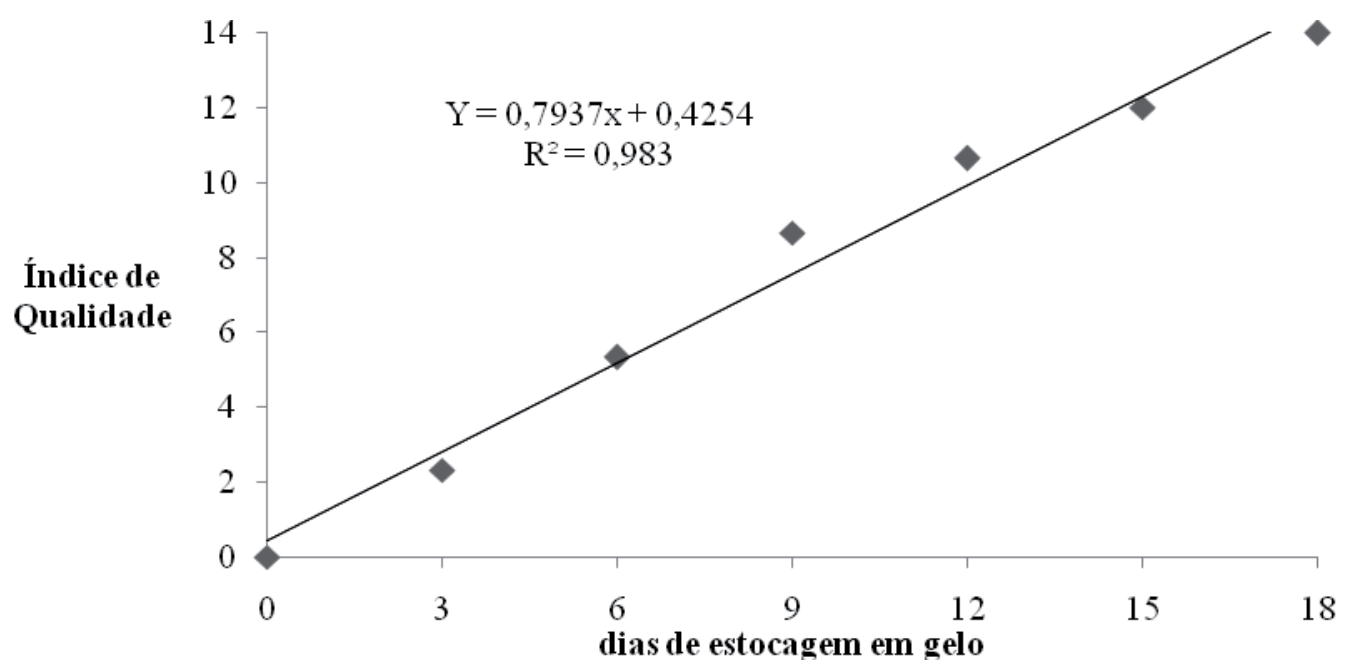

Fonte: Elaboração dos autores.

Os parâmetros sensoriais significativos para filés sem pele de tilápia do Nilo estão descritos no quadro 1 e estão relacionados com a musculatura do filé. A cor da musculatura variou ao longo do armazenamento de rosa claro, brilhante a bege escurecido opaco, característico de carne de peixe velha, deteriorada. A quantidade de muco e sua viscosidade aumentaram com o armazenamento. O cheiro do filé passou por quatro estágios bem definidos, recebendo quatro escores ao longo da estocagem ( 0 - fresco; 1 - não fresco, mas neutro; 2 - amoniacal; 3 - pútrido).

A textura apresentou-se firme até o sexto dia em gelo, variando posteriormente para ligeiramente mole, mole, completamente autolisada. Este último estágio foi observado aos 18 dias de estocagem e se caracterizou pela desfragmentação do filé ao toque forçado dos dedos dos julgadores. A cor do sangue presente nos filés também variou de vermelho vivo a marrom. Outro atributo sensorial importante foi a disposição das fibras musculares, observando-se a presença ou ausência de gaping. Segundo Lavéty
(2011) gaping são fendas entre os blocos musculares do filé, podendo variar de uma ligeira separação em uma pequena área ou ter uma abrangência maior. $\mathrm{O}$ gaping prejudica a aparência dos filés, prejudicando sua comercialização por depreciar sua sua aparência sensorial. Botta (1995) afirma que com o gaping o músculo perde a aparência de um músculo contínuo.

No presente estudo, observou-se uma estabilização nos blocos musculares com ausência de gaping ou presença de pequenas aberturas até o $6^{\circ}$ dia de estocagem. A partir dos 15 dias, o gaping comprometeu mais de $75 \%$ dos filés, prejudizando o aspecto sensorial. A figura 2 representa o gaping na musculatura dos filés de tilápia do Nilo. Os blocos musculares denominados miômeros ou miotomas são segmentados regularmente por divisórias de tecido conjuntivo chamadas mioseptas. A explicação possível para este fenômeno é que com o decorrer do armazenamento, possivelmente, processos autolíticos e ação bacteriana enfraquecem essas divisórias, permitindo a separação dos blocos musculares, caracterizando o gaping. 
Figura 2. Gaping em filés de tilápia do Nilo (Oreochromis niloticus) aos 15 dias de armazenamento.

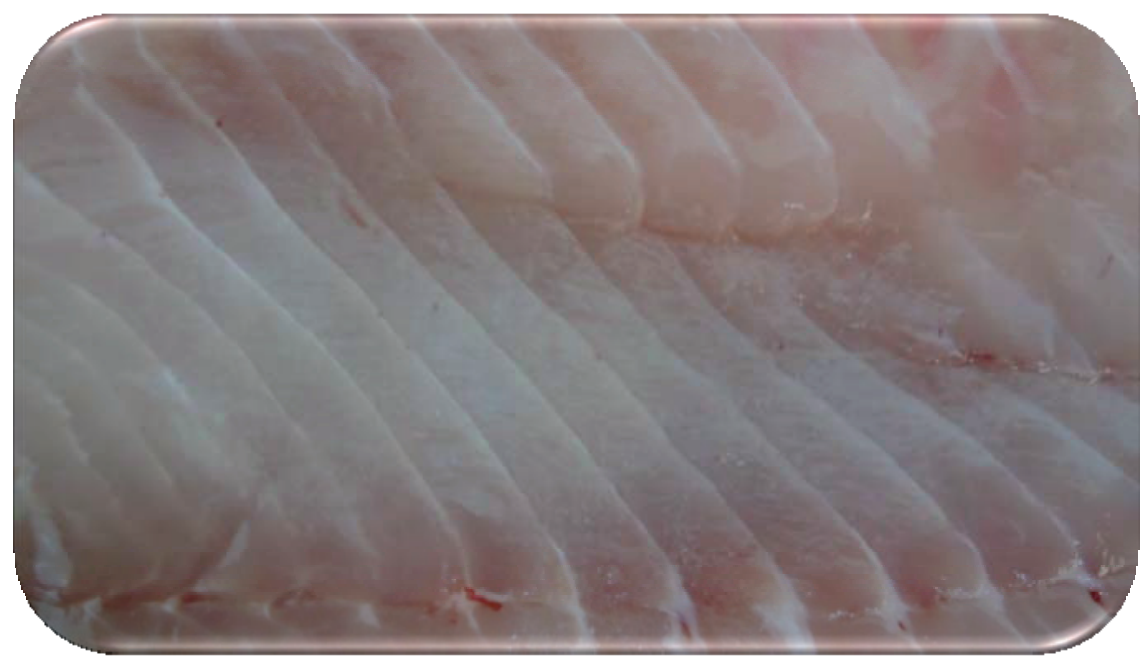

Fonte: Elaboração dos autores.

Bonilla, Sveinsdottir e Martinsdottir (2007), avaliando o gaping em filés de bacalhau (Gadus morhua), vericaram que, para filés desta espécie, alterações no gaping são mais acentuadas no início do período de armazenamento, até 7 dias de estocagem, ou seja, de forma contrária ao que foi detectado no presente estudo, onde observou-se mudanças mais acentuadas na separação dos blocos musculares no final do período de estocagem.

A mudança mais intensa no IQ para filés de tilápia ocorreu do $6^{\circ}$ para o $9^{\circ}$ dia de estocagem. Neste período, o IQ médio aumentou de 5,33 para 8,66. O IQ de rejeição para o filé foi de 12 pontos atingidos aos 15 dias em gelo. A figura 3 representa a evolução sensorial dos filés de tilápia do Nilo durante a estocagem em gelo até o dia de rejeição sensorial aos 15 dias. Neste dia de avaliação, observou-se uma grande quantidade de muco viscoso, cheiro amoniacal e textura mole. Outra característica marcante ao longo do período de armazenamento e que se intensificou aos 15 dias foi a modificação na disposição das fibras musculares, caracterizando o gaping.
Odoli (2009) estudou o MIQ para filés de tilápia, armazenadas a $1^{\circ} \mathrm{C}$ e encontrou resultados semelhantes ao presente trabalho. A vida de prateleira foi estimada em 13 a 15 dias para filés estocados a $1^{\circ} \mathrm{C}$. Soccol (2002) ao avaliar sensorialmente filés de tilápia do Nilo, através de metodologia diferente do MIQ, constatou que filés submetidos a tratamento sob atmosfera modificada e ácido acético foram considerados aceitáveis até o $13^{\circ}$ dia em gelo. Bonilla, Sveinsdottir e Martinsdottir (2007) estudaram o MIQ para filés de bacalhau estocados em refrigeração e estimaram uma vida de prateleira máxima de 14 dias em gelo, enquanto, Magnússon e Martinsdóttir (1995) em estudo semelhante consideraram a vida útil de filés de bacalhau em 10 a 12 dias.

Aos 18 dias em gelo, os filés estavam completamente deteriorados, atingindo a máxima pontuação do esquema MIQ, 14 pontos. O cheiro apresentou-se intensamente pútrido e a musculatura completamente mole, autolisada e a cor bege opaca, intercalada com manchas rosadas escurecidas. 
Figura 3. Evolução sensorial da musculatura do filé sem pele de tilápia do Nilo (Oreochromis niloticus) durante o armazenamento em gelo por $0,3,6,9,12$ e 15 dias.
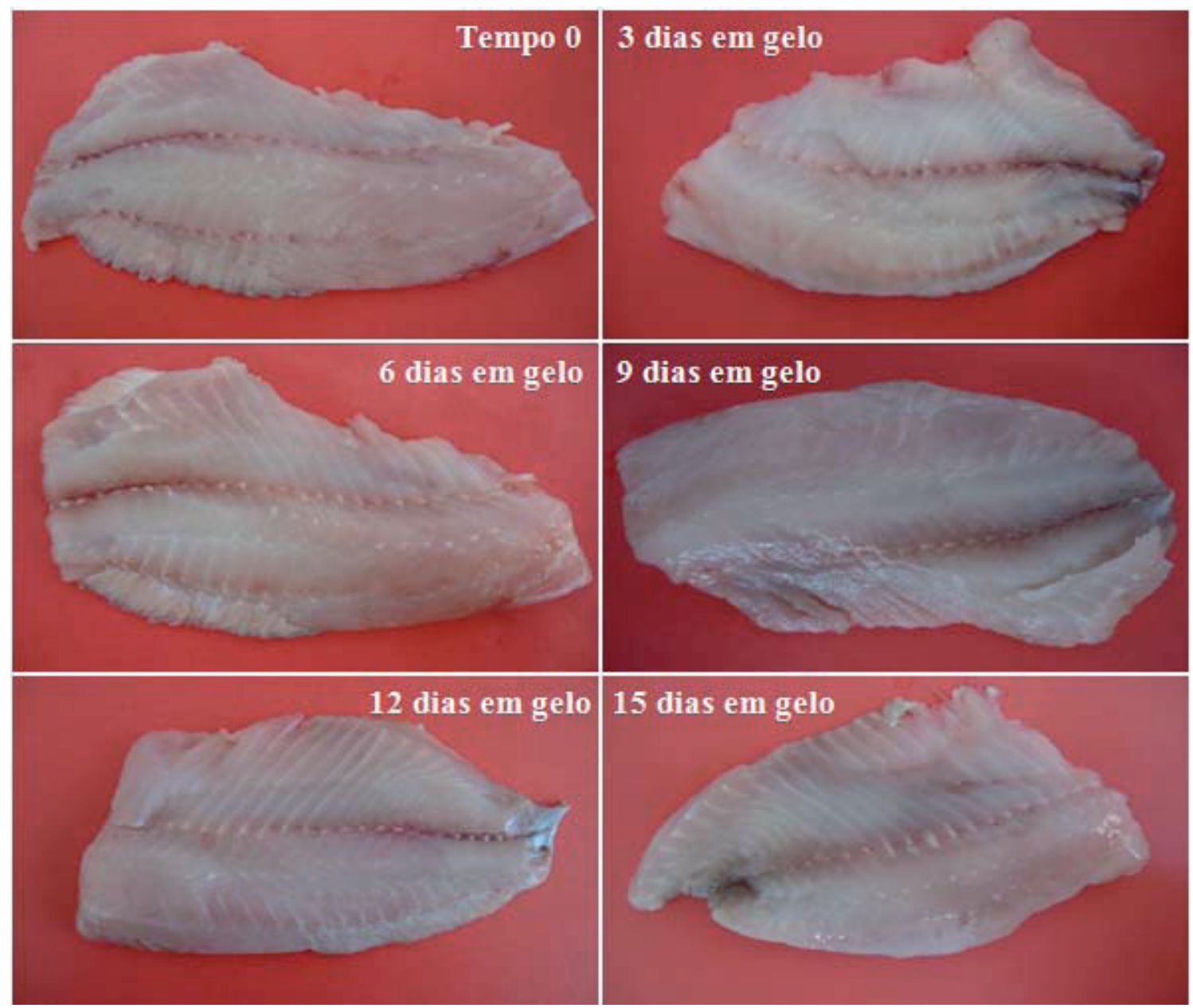

Fonte: Elaboração dos autores.

\section{Análises fisico-químicas}

A figura 4 representa a evolução do $\mathrm{pH}$ para os filés de tilápia durante o armazenamento. O menor valor de $\mathrm{pH}$ encontrado foi de 5,9 e o maior foi de
7,11. A partir do $15^{\circ}$ dia de estocagem em gelo, o $\mathrm{pH}$ atingiu valor acima do permitido pela legislação brasileira, o que coincidiu com o período de rejeição sensorial pelo MIQ (Figura 4). 
Figura 4. Valores de pH em função dos dias de estocagem de filés de tilápia do Nilo (Oreochromis niloticus) armazenados em gelo por 18 dias.

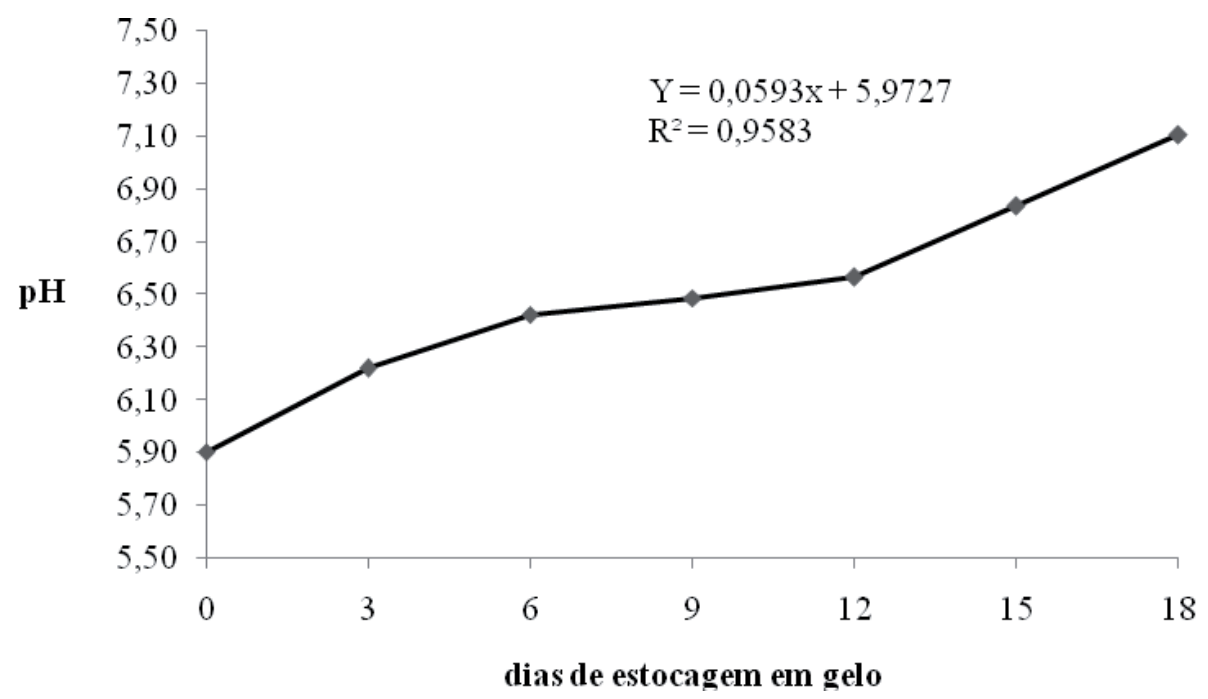

Fonte: Elaboração dos autores.

Os valores de $\mathrm{pH}$ encontrados em filés de tilápia do Nilo, no presente trabalho, discordam dos valores obtidos por Odoli (2009), este autor registrou uma variação de $\mathrm{pH}$ de 6,5 a 6,7 durante a estocagem de filés de tilápia do Nilo a $1^{\circ} \mathrm{C}$. Almeida et al. (2006) encontraram variação de $\mathrm{pH}$ de 6,07 a 6,66 durante armazenamento de tambaqui por 49 dias em gelo. $\mathrm{O}$ pH inicial encontrado no presente estudo $(5,90)$, quando comparado à outras pesquisas, pode ser considerado baixo. Este resultado, possivelmente, pode ser explicado, pelo fato das tilápias avaliadas no presente estudo procederem de um sistema de cultivo em tanques rede, o que certamente demanda um menor tempo para os animais se debaterem até o momento da captura, resultando em uma maior preservação do teor inicial de glicogênio e, consequentemente, em um maior acúmulo de ácido lático, produzido principalmente por via anaeróbica, refletindo em baixos valores de $\mathrm{pH}$ iniciais. Por esta razão, as medidas de $\mathrm{pH}$ encontradas nos primeiros dias de armazenamento em gelo provavelmente seriam maiores, caso os peixes fossem provenientes de um sistema extensivo ou semi-intensivo, o que possivelmente explica a diferença das medidas iniciais encontrados no presente estudo e as encontrados por outros autores. Kai e Morais (1988) ressaltam que a queda do $\mathrm{pH}$, em decorrência da morte do pescado, é rápida, e depende, entre outros fatores, das condições de captura, pois as reservas de glicogênio dependem da resistência com que os peixes se opõem à captura. Esses valores vão aumentando com a estocagem, à medida que a deterioração ocorre. $\mathrm{O}$ aumento do valor do $\mathrm{pH}$ com o armazenamento é decorrente do acúmulo de N-BVT, formada a partir de atividades autolíticas e bacterianas (OGAWA; MAIA, 1999).

O teor de N-BVT dos filés de tilápia variou de 5,58 a $31,55 \mathrm{mg} \mathrm{N} / 100 \mathrm{~g}$, respectivamente, nos dias 0 e 18 (Figura 5). 
Figura 5. Teores de N-BVT em função dos dias de estocagem de filés de tilápia do Nilo (Oreochromis niloticus), cultivada, armazenados em gelo por 18 dias.

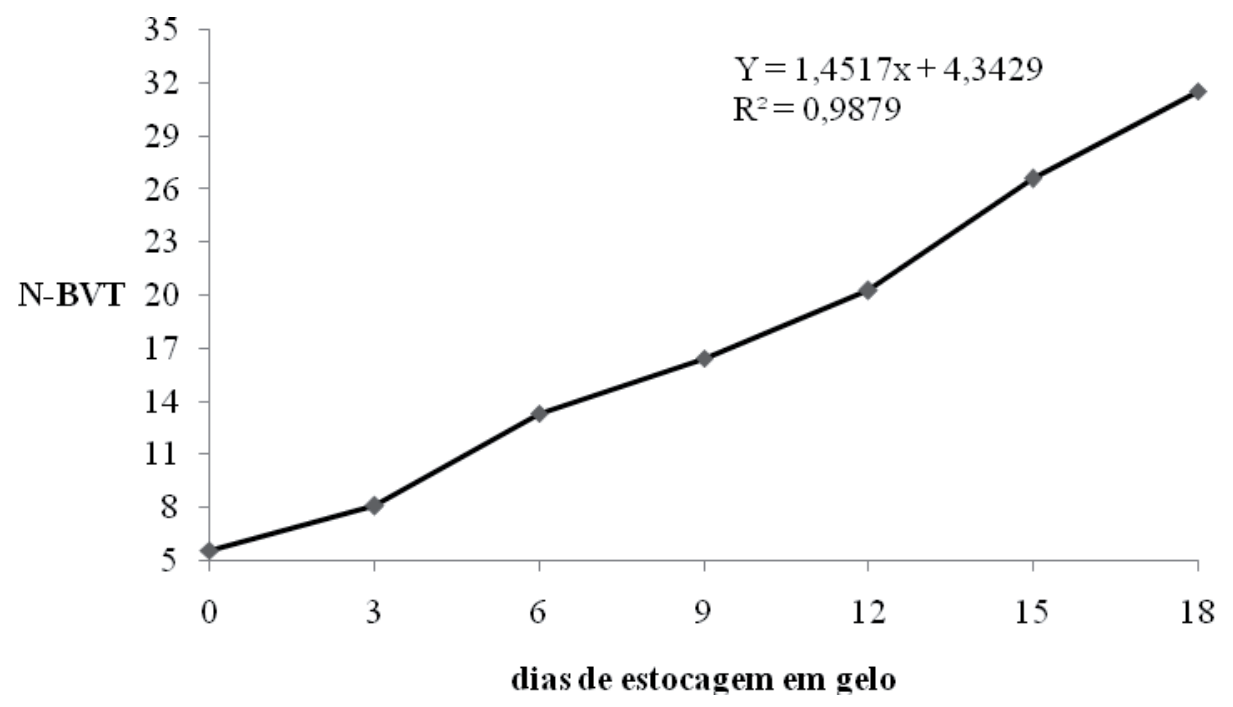

Fonte: Elaboração dos autores.

Apesar dos teores de N-BVT obtidos no presente estudo terem seguido um padrão esperado, aumentando com o tempo de armazenamento, esta análise não pode ser considerada segura para avaliar a qualidade de filés de tilápia, pois no $15^{\circ}$ dia de estocagem (ponto de rejeição sensorial), a análise de N-BVT resultou em valores inferiores ao limite estabelecido pela legislação brasileira que é de 30 mg N/100g (BRASIL, 1997). Soccol (2002) estudou a vida útil de filés de tilápia do Nilo, submetidos a diferentes tratamentos e estocados em refrigeração, encontrando valores de N-BVT inferiores a $30 \mathrm{mg}$ de $\mathrm{N} / 100 \mathrm{~g}$ durante todo o período de armazenamento. Este autor verificou que as amostras de filé de tilápia controle apresentaram médias de N-BVT variando de 14 a 18,9 mg de N/100g nos dias 1 e 20, respectivamente.

Em contrapartida, outros autores ao realizarem pesquisas em espécies de pescado diferentes da espécie estudada no presente trabalho, consideram a análise de N-BVT eficiente na avaliação de frescor, como Vaz-Pires et al. (2008) que, ao realizarem pesquisa com armazenamento do moluscosiba(Sepia officinalis), detectaram alterações significativas nos teores de N-BVT a partir da primeira semana de armazenamento em gelo, considerando esta análise como importante método para avaliar o frescor para a espécie estudada. Já Damasceno (2009) realizou análise de N-BVT em salmão comercializados em Belo Horizonte e verificou que esta análise não se correlacionou à análise sensorial. Este autor ressalta que, em sua pesquisa, alguns peixes, nos quais as características sensoriais eram indesejáveis, os teores de N-BVT eram normais, sendo às vezes até melhores do que alguns peixes com características sensoriais desejáveis.

Estes fatos reforçam a heterogeneidade existente entre os parâmetros de qualidade entre as diversas espécies de pescado, que se deterioram de formas distintas, afirmando a importância de se rever algumas legislações, como a brasileira, que prevê um valor máximo de N-BVT de $30 \mathrm{mgN} / 100 \mathrm{~g}$ para todas as espécies de pescado. Este padrão também é adotado por muitas legislações internacionais que preconizam a qualidade do pescado (CONTRERASGUZMÁN, 1994). Ogawa e Maia (1999) ressaltam que pescado em excelente de frescor, o teor de N-BVT é de 5 a $10 \mathrm{mg} \mathrm{N} / 100 \mathrm{~g}$, enquanto pescado 
com frescor razoável os teores podem atingir 15 a $25 \mathrm{mg} \mathrm{N} / 100 \mathrm{~g}$.

Os teores de N-BVT encontrados no presente estudo foram superiores aos obtidos por Odoli (2009) que encontrou teores de N-BVT de $21,3 \mathrm{mg}$ $\mathrm{N} / 100 \mathrm{~g}$ aos 20 dias de estocagem de filés de tilápia em armazenamento refrigerado. Tal resultado de N-BVT pode ser explicado pelo fato dos filés terem sido embalados em sacos plásticos antes do armazenamento em gelo, o que, provavelmente, diminui a possibilidade de lixiviação de compostos químicos. Outra explicação são as variações decorrentes na variação da metodologia utilizada (KUAYE, 1982), ou até mesmo mudanças decorrentes da época de captura. Watanabe (1972) afirma que os valores de N-BVT sofrem variações maiores, quando os peixes são capturados no período de fim de ano.

Gonçalves (2011) afirma que testes químicos que se baseiam na formação de metabólitos só detectam a formação dos mesmos quando a velocidade de formação exceder a velocidade de lixiviação. Este autor reforça que esta é uma das principais deficiências de alguns testes objetivos de frescor, particularmente quando se trata de pescado.

A tabela 2 representa os principais parâmetros de qualidade dos filés de tilápia nos dias de avaliação estudados. Observa-se que o MIQ foi a ferramenta mais criteriosa para estabelecer o ponto de rejeição dos filés de tilápia do Nilo, ou seja, a avaliação subjetiva foi mais segura que os métodos objetivos na estimativa de qualidade. No dia 15 , que foi o limite máximo de vida útil dos filés, estes ainda possuíam teores aceitáveis de N-BVT, segundo a legislação brasileira. Em contrapartida, Soares et al. (1998) ao avaliarem a qualidade físico-química de filé de peixe congelado observaram que a análise de N-BVT foi mais segura que a análise sensorial, pois enquanto todas as amostras foram consideradas seguras pela análise sensorial, a maioria não atendia os requisitos para N-BVT. Pereira e Tenuta-Filho (2005) também consideraram o teor de N-BVT uma importante ferramenta de avaliação de frescor em sardinhas provenientes de comércio atacadista e de feiras livres encontrando médias de N-BVT de 15,75 e $27,06 \mathrm{mg} \mathrm{N} / 100 \mathrm{~g}$ de músculo, respectivamente, ou seja, os autores constataram que a média dos valores de N-BVT dos peixes oriundos de feiras livres é $71,8 \%$ maior quando comparada à média obtida a partir das amostras do comércio varejista, ou seja, diferenças em decorrência das condições de manuseio e estocagem do pescado.

O ponto de rejeição pelo MIQ coincidiu com a rejeição pelo $\mathrm{pH}$, ou seja este método foi eficiente na estimativa de frescor, comportamento que também foi detectado por Soccol (2002) ao avaliar filés de tilápia do Nilo minimamente processados.

Tabela 2. Parâmetros de qualidade sensorial e físico química (médias e desvio padrão) de filés sem pele de tilápia do Nilo (Oreochromis niloticus) armazenados em gelo durante 18 dias.

\begin{tabular}{cccc}
\hline Dia & $\mathrm{IQ}$ & $\mathrm{pH}$ & $\mathrm{N}-\mathrm{BVT}(\mathrm{mg} \mathrm{N} / 100 \mathrm{~g})$ \\
\hline $\mathbf{0}$ & $0,00( \pm 0,00)$ & $5,90( \pm 0,01)$ & $5,58( \pm 0,58)$ \\
$\mathbf{3}$ & $2,33( \pm 0,58)$ & $6,22( \pm 0,12)$ & $8,08( \pm 0,71)$ \\
$\mathbf{6}$ & $5,33( \pm 0,58)$ & $6,43( \pm 0,04)$ & $13,31( \pm 2,24)$ \\
$\mathbf{9}$ & $8,67( \pm 1,53)$ & $6,49( \pm 0,02)$ & $16,45( \pm 1,19)$ \\
$\mathbf{1 2}$ & $10,67( \pm 0,58)$ & $6,57( \pm 0,09)$ & $20,28( \pm 1,36)$ \\
$\mathbf{1 5}$ & $12,00( \pm 0,00)$ & $6,84( \pm 0,18)$ & $26,61( \pm 0,61)$ \\
$\mathbf{1 8}$ & $14,00( \pm 0,00)$ & $7,11( \pm 0,09)$ & $31,55( \pm 1,86)$ \\
\hline
\end{tabular}

Fonte: Elaboração dos autores. 


\section{Conclusões}

O esquema MIQ para filés de tilápia tem pontuação variando de 0 a 14 pontos. O ponto de rejeição dos filés de tilápia foi atingido no $15^{\circ}$ dia em gelo, correspondendo a um IQ médio de 12 pontos. A pontuação máxima de IQ do esquema foi atingida no $18^{\circ}$ dia em gelo dos filés. Neste dia, os filés estavam completamente deteriorados.

O MIQ foi eficiente para avaliar o frescor e a qualidade dos filés mantidos em gelo. A medição de N-BVT não é um método seguro para avaliar o frescor dos filés tilápia do Nilo, pois mesmo quando os filés foram rejeitados pelo MIQ, os níveis de N-BVT estavam dentro dos padrões permitidos pela legislação brasileira.

Portanto, a vida útil dos filés de tilápia do Nilo armazenados em gelo pode ser estimada em no máximo 15 dias.

\section{Referências}

ALMEIDA, N. M.; BATISTA, G. M.; KODAIRA, M.; LESSI, E. Alterações pos mortem em tambaqui (Colossoma macropomum) conservados em gelo. Ciência Rural, Santa Maria, v. 36, n. 4, p. 1288-1283, 2006.

BAIXAS-NOGUERAS, S.; BOVER-CID, S.; VECIANA-NOGUÉS, T.; NUNES, M. L.; VIDALCAROU, M. C. Development of a Quality Index Method to evaluate freshness in Mediterranean Hake (Merluccius merluccius). Journal of Food Science, Chicago, v. 68, n. 3, p. 1067-1071, 2003.

BOGDANOVIC, T.; SIMAT, V.; FRKA-ROI'C, A.; MARKOVI, K. Development and application of Quality Index Method scheme in a shelf-life study of wild and fish farm affected bogue (Boops boops, L.). Journal of Food Science, Chicago, v. 77, n. 2, p. S99, S106, 2012.

BONILLA, A. C.; SVEINSDOTTIR, K.; MARTINSDOTTIR, E. Development of quality index (QIM) scheme for fresh cod (Gadus morhua) fillets and application in shelf life study. Food Control, Vurrey, v. 18, p. 352-358, 2007.

BOTTA, J. R. Evaluation of seafood freshness quality. New York: VCH Publishers, 1995.
BRASIL. Ministério da Agricultura, Pecuária e Abastecimento. Regulamento da inspeção industrial e sanitária de produtos de origem animal. Brasília: Ministério da Agricultura, Pecuária e Abastecimento, 1997.

CONTRERAS-GUZMÁN, A. Bioquímica do pescado e derivados. Jaboticabal: FUNESP, 1994. 409 p.

COSTELL, E. A comparison of sensory methods in quality control. Food Quality and Preference, Oxford, v. 13, n. 6, p. 341-353, 2002.

DAMASCENO,A.Qualidade(sensorial, microbiológica, físico-química e parasitológica) de salmão (Salmo salar, Linnaeus, 1778) resfriado, comercializado em Belo Horizonte - MG. 2009. Dissertação (Mestrado em Ciência Animal) - Escola de Veterinária da Universidade Federal de Minas Gerais. Universidade Federal de Minas Gerais, Belo Horizonte.

GERMANO, P. M. L.; GERMANO, P. M. L. Higiene e vigilância sanitária de alimentos. 3. ed. São Paulo: Manole, 2008. 986 p.

GODOY, C. E. Produção da tilápia do Nilo, Oreochromis niloticus (L, 1758), linhagem Chitralada, de pequeno porte, em tanques-rede visando o atendimento de comunidades carentes. 2006. Dissertação (Mestrado em Recursos Pesqueiros e Aqüicultura) - Universidade Federal Rural de Pernambuco, Recife.

GONÇALVES, A. A. Tecnologia do pescado: ciência, tecnologia, inovação e legislação. São Paulo: Ateneu, 2011, $608 \mathrm{p}$.

HYLDIG, G.; NIELSEN, J. A rapid method for quality management. In: OLAFSDÓTTIR, G.; LUTEN, J.; DALGAARD, P.; CARECHE, M.; VERREZ-BAGNIS, V.; MARTINSDOTTIR, E.; HEIA, K. (Ed.). Methods to determine the freshness of fish in research and industry. Paris: International Institute of Refrigeration, 1997.

JENSEN, H. S.; JØRGENSEN, B. M. A sensometric approach to codquality measurement. Food Quality and Preference, Oxford, v. 8, n. 5-6, p. 403-407, 1997.

KAI, M.; MORAIS, C. Vias de deterioração do pescado. In: KAI, M.; RUIVO, U. E. Controle de qualidade do pescado. Santos: Leopoldianum, 1988. p. 13-20.

KUAYE, A. Y. Comparação dos métodos para determinação das bases nitrogenadas em pescado: parâmetros críticos e modificações. 1982. Dissertação (Mestrado em Engenharia de Alimentos) - Faculdade de Engenharia de Alimentos e Agrícola. Universidade Estadual de Campinas, Campinas. 
LABORATÓRIO NACIONAL DE REFERÊNCIA ANIMAL - LANARA. Métodos analíticos oficiais para controle de produtos de origem animal e seus ingredientes. II - Métodos físicos e químicos, Brasília: Ministério as Agricultura, 1981. (Apostila).

LAVÉTY, J. Gaping in farmed salmon and trout. 2011. Disponível em: <http://www.fao.org/wairdocs/tan/ x5958e/x5958e00.htm\#Contents.>. Acesso em: $12 \mathrm{dez}$. 2011.

LUTEN, J. B.; MARTINSDOTTIR, E. QIM: a European tool for fish freshness evaluation in the fishery chain. Paris: International Institute of Refrigeration. 1997. 396 p.

MAGNÚSSON, H.; MARTINSDÓTTIR, E. Storage quality of fresh and frozen-thawed fish in ice. Journal of Food Science, Chicago, v. 60, n. 2, p. 273-278, 1995.

MARTINSDOTTIR, E.; SVEINSDOTTIR, K.; LUTEN, J. B.; SCHELVIS-SMIT, R.; HYLDIG, G. Reference manual for the fish sector: sensory evaluation of fish freshness. Netherlands: QIM Eurofish. P.O. Box 68, 1970 AB I Jmuiden, 2001.

MINISTÉRIO DA PESCA E AQUICULTURA - MPA. Informações e estatisticas. 2011. Disponível em: <http:// www.mpa.gov.br/.>. Acesso em: $11 \mathrm{dez} .2011$.

NUNES, M. L.; BATISTA, I.; CARDOSO, C. Application of quality index (QIM) in the evaluation of the freshness of fish. Lisboa: IPIMAR, 2007. $51 \mathrm{p}$.

ODOLI, C. O. Optimal storage conditions for fresh farmed tilapia (Oreochromis niloticus) fillets. 2009. Thesis (Masters in Science) - University of Iceland, Iceland.

OGAWA, M.; MAIA, E. L. Manual da pesca: ciência e tecnologia do pescado. São Paulo: Varela, 1999. 430 p.

OLAFSDÓTTIR, G.; MARTINSDÓTTIR, E.; OEHLENSCHLAGER, J.; DALGAARD, P.; JENSEN, B.; UNDELAND, I.; MACKIE, I. M.; HENEHAN, G.; NIELSEN, J.; NIELSEN, H. Methods to evaluate fish freshness in research and industry. Trends in Food Science \& Technology, Cambridge, v. 8, n. 8, p. 258-265, 1997.

OLIVEIRA, V. M.; CLEMENTE, S. C. S.; MÁRSICA, E. T. Método do indice de qualidade (MIQ) desenvolvido para camarão (Litopenaeus vannamei) cultivado. Revista de Ciências da Vida, Rio de Janeiro, v. 29, n. 1, p. 60-71, jan./jun. 2009.
OMONDI, J. G.; GICHURI, W. M.; VEVERICA, K. A partial economic analysis for Nile tilapia Oreochromis niloticus L. and sharptoothed catfish Clarias gariepinus (Burchell, 1822) polyculture in central Kenya. Aquaculture Research, Amsterdam, v. 32, n. 9, p. 693700, 2001.

PEREIRA, A. A. F.; TENUTA-FILHO, A. Avaliação de condições de consumo da sardinha Sardinella brasiliensis. Ciência e Tecnologia de Alimentos, Campinas, v. 25, n. 4, p. 720-725, 2005.

SOARES, F. M. V.; VALE, S. R.; JUNQUEIRA, R. G.; GLÓRIA, M. B. A. Teores de histamina e qualidade físico-química sensorial de filé de peixe congelado. Ciência e Tecnologia de Alimentos, Campinas, v. 18, n. 4, p. 462-470, 1998.

SOCCOL, M. C. H. Otimização da vida útil da tilápia cultivada (Orechoromis niloticus), minimamente processada e armazenada sob refrigeração. 2002. Dissertação (Mestrado em Ciência e Tecnologia de Alimentos) - Escola Superior de Agricultura Luiz de Queiroz. Universidade de São Paulo, São Paulo.

SVEINSDOTTIR, K.; HYLDIG, G.;MARTINSDOTTIR, E.; JORGENSEN, B.; KRISTBERGSSON, K. Quality index method (QIM) scheme developed for farmed Atlantic salmon (Salmo salar). Food Quality and Preference, Oxford, v. 14, n. 3, p. 237-245, 2003.

SYKES, A. V.; OLIVEIRA, A. R.; DOMINGUES, P. M.; CARDOSO, C. M.; ANDRADE, J. P.; NUNES, M. L. Assessment of European cuttlefish (Sepia officinalis, L.) nutritional value and freshness under ice storage using a developed Quality Index Method (QIM) and biochemical methods. LWT - Food Science and Technology, London, v. 42, n. 1, p. 424-432, 2009.

VAZ-PIRES, P.; SEIXAS, P.; MOTA, M.; LAPAGUIMARÃES, J.; PICKOVA, J.; LINDO, A.; SILVA, T. Sensory, microbiological, physical and chemical properties of cuttlefish (Sepia officinalis) and broadtail shortfin squid (Illex coindetii) stored in ice. LWT - Food Science and Technology, London, v. 41, n. 9, p. 16551664, 2008.

WARM, K.; BOKNAES, N.; NIELSEN, J. Development of quality index methods for evaluation of frozen cod (Gadus morhua) and cod fillets. Journal of Aquatic Food Products Technology, London, v. 7, n. 1, p. 45-59, 1998.

WATANABE, K. Spoilage in ice pescada foguete (Macrodon ancylodon) from south brasilian fishing grounds. Separata do Boletim do Instituto Oceanografico, Torno, v. 2, p. 65-80, 1972. 